\title{
ANNOTATION
}

\section{Eye Injuries among Stone Breakers}

Among the writer's very early recollections of his childhood when he lived in the depth of the country are the village blacksmith in his smithy, the pedlar and his pack, a morose individual, the local butcher, who still wore the agriculturalists' smock frock, and the road mender breaking stones at the side of the road. The last named wore large protective goggles to avoid eye injuries. He was a formidable figure to the infant mind, and the goggles, made we believe of a fine wire mesh, added to the feeling of fear which his appearance at first sight engendered. In reality he was a most respectable member of my father's congregation and, without the goggles, very pleasant company.

We have recently been making enquiries as to the frequency of eye injuries among the flint knappers of East Anglia. This must certainly be one of the oldest occupations in the world and we are informed that injury to the eyes is exceedingly rare among them. Much of their work is done on a leather shield strapped on to the left leg above the knee, though the finer work is done on a bench. The knapper knows by long experience how to place his flint. These large flints mostly have flaws in them and the knapper percusses with his hammer with light taps until he has found the right spot and then gives a smart blow on it. Fragments appear to fly downwards and sideways and perhaps this may account for the rarity of eye injuries. This part of his work is rather different from that of the road mender whose fragment of stone lies on a bed of similar fragments, or on the ground nearby, with very little resilience beneath it. The bench work would seem more nearly to approximate that of the road mender, but so far as we could learn injury to the eye is very rare and the few knappers who still ply their trade do not wear, so far as we know, any form of eye protection.

\section{ABSTRACTS}

\section{MISCELLANEOUS}

(1) Danielson, R. W. and Long, J. C. (Denver, Colorado).Keratitis due to mumps. Amer. Jl. Ophthal., Vol. XXIV, p. 655, 1941.

(1) Danielson and Long comment on the rarity of keratitis associated with epidemic parotitis and state that only 7 cases have been reported in the literature. The disease arises 2 to 11 days 
after the onset of the parotid swelling, affects one eye only and lasts for 7 to 30 days. Recovery is generally complete or almost so. In the case they report of a boy, aged 9, keratitis occurred in the right eye 3 days after parotitis began and recovery was almost complete in 12 days. The slit-lamp showed white inter-lacing fibrillae in the thickened substantia propria and striate wrinkling of Descemet's membrane. There was no uveal involvement.

H. B. STALLARD.

(2) Thompson, R. and Gallardo, E. (New York).-The antibacterial action of tears on staphylococci. Amer. Jl. Ophthal., Vol. XXIV, p. 635, 1941.

(2) Thompson and Gallardo review the literature about the anti-bacterial action of tears on staphylococci. They comment on the work and conceptions of several authors on the subject and quote Frederick Ridley's experiments which showed that a slight decrease in tear concentration resulted in a complete loss of antibacterial action. Ninety per cent. tear concentrations killed pneumococci but these organisms grew in 75 per cent. concentrations. Lysozyme is a basic protein or polypeplide enzyme that is soluble and extremely heat-resistant in acid solution these properties afforded a means of separating it from other anti-bacterial agents that might be present in tears.

Diluted 18 hour broth cultures of orange, mannitol-fermenting, coagulase producing staphylococci were considered pathogenic. Fifty per cent. and 25 per cent. dilution of tears in infusion broth were prepared. Five hundredth's of a c.c. of the culture dilutions were added to 0.25 c.c. of the tear mixtures in small tubes and to the same quantities of 50 per cent. saline broth mixture and incubated at $37^{\circ} \mathrm{C}$. for 18 hours. Comparisons were made in the degree of clouding of the solutions and plating out on agar uniform loops of various mixtures at the beginning of the experiment and at 3,6 , and 18 hour periods.

The non-pathogenic, white, mannitol coagulase-negative strains of staphylococci were more susceptible to the action of tears than the pathogenic. There was a rapid disappearance of anti-bacterial activity in the dilutions of the tears. Fifty per cent. concentration of the tears in broth inhibited the growth of 15 of 16 orange, mannitol fermenting, coagulase producing staphylococci but these micro-organisms grew well in 25 per cent. tear concentration. All the staph-albus preparations were inhibited by 50 per cent. tear concentration and a number by 25 per cent. tear concentration. This action was not due to lysozyme since heated, acidified tears lost all trace of anti-staphylococcal action although the lysozyme content was unaffected by heating.

H. B. Stallard. 